\title{
Dostoievski: una lección de anatomía desde el subsuelo
}

\author{
Dostoevsky: \\ an Anatomy Lesson from the Underground
}

LORENA RIVERA LEÓN

\begin{abstract}
Resumen: El artículo está centrado en los Apuntes del subsuelo de F. M. Dostoievski. Se aborda la presencia del cuerpo en esta novela breve que marca el punto de inflexión hacia lo que muchos estudiosos han considerado una filosofía trágica en la obra del escritor ruso. La Lección de anatomía del Dr. Joan Deijman, pintada por Rembrandt en 1656, brinda el contrapunto para dilucidar cuál es la concepción de la naturaleza humana que Dostoievski delinea en esta obra.

Palabras clave: Dostoievski, cuerpo, tragedia, literatura comparada, antropología filosófica y literatura.
\end{abstract}

\begin{abstract}
The article focuses on Notes from the Underground by F. M. Dostoevsky. It analyses the presence of the body in this short novel considered by many scholars a turning point in Dostoevsky's career because here begins what has been called the philosophy of tragedy in his work. The Anatomy Lesson of Dr. Joan Deijman, painted by Rembrandt in 1656 , offers a counterpoint to elucidate the conception of human nature that Dostoevsky delineates in this work.
\end{abstract}

Keywords: Dostoevsky, body, tragedy, comparative literature, philosophical anthropology and literature.

Fiódor M. Dostoievski pertenece a esa selecta nómina de literatos cuya obra ha interesado desde siempre a los filósofos. Resulta revelador que Friedrich Nietzsche (1998, 129), que tuvo un acceso muy limitado a sus textos, se refiriera a él en estos términos en el aforismo 45 de Crepúsculo de los ídolos: «Dostoievski, el único psicólogo, dicho sea de paso, del que yo he tenido que aprender algo». A partir de un estudio de Lev I. Shestóv ${ }^{1}$

Fecha de recepción: 31/05/2016 Fecha de aceptación: 06/09/2016.

* Lorena Rivera León es doctora en Filosofía por la Universitat de València, la misma institución donde se licenció y fue becaria de investigación FPU del Ministerio de Educación. En la actualidad trabaja como profesora de Filosofía en el IES El Olivo de Parla (Madrid). Su tesis lleva por título El amor en Dostoievski: un estudio desde la antropología filosófica, pues la relación entre filosofía y literatura constituye su principal interés investigador y cuenta por ello con diversas publicaciones en este campo. Entre las más recientes cabe citar «La risa es un asunto serio: lo carnavalesco en El idiota (Dostoievski y Kurosawa)», en: Sonia París Albert e Irene Comins Mingol (eds.), La interculturalidad en diálogo: estudios filosóficos, Estudios Thémata, Sevilla, 2016, pp. 283-293 y «Lo que Dios no ha unido, lo conecta el hombre», Pasajes: Revista de Pensamiento Contemporáneo, $\mathrm{n}^{\circ}$ 47, 2015, pp. 108-123. Correo electrónico: Lorena.Rivera@uv.es 
(1949) en torno a Dostoievski y Nietzsche devenido en un clásico, ha tomado fuerza una corriente que ve emerger de las creaciones del novelista ruso una filosofía de la tragedia. Cuerpo y tragedia es, precisamente, el tema del texto que el lector tiene entre sus manos. Los Apuntes del subsuelo, a los que está dedicado el presente artículo, marcan, en opinión de la mayoría de expertos, el punto de inflexión entre una primera etapa ligada a lo que el propio Dostoievski designaría como «schillerismo», entendiendo por tal un idealismo romántico y sentimentalista propio de la generación de los años cuarenta, y el período de genio del escritor donde se perfila una concepción trágica de la existencia. Nikolái A. Berdiáev, cuya monografía sobre Dostoievski está entre los clásicos de la historia hermenéutica sobre el escritor, defiende inequívocamente esta idea, como se aprecia en el siguiente pasaje:

Las memorias del subsuelo divide la obra de Dostoievski en dos períodos. Hasta entonces, Dostoievski no era todavía más que un psicólogo, original, sin duda, al mismo tiempo que humanitario y compasivo con la «pobre gente», con los «humillados y ofendidos», con los protagonistas de La casa de los muertos. Las memorias del subsuelo inauguran la genial dialéctica de la idea de Dostoievski. Deja de ser solamente un psicólogo para convertirse en un metafísico que explora hasta el extremo la tragedia del espíritu humano. [...] Dostoievski es un escritor trágico. (Berdiáev, 2008, 23-24)

George Steiner, que, en su también clásico estudio comparativo entre Dostoievski y Lev $\mathrm{N}$. Tolstói, se refiere al primero como «uno de los más grandes poetas trágicos» (Steiner, 2002, 19), no duda en afirmar, en relación con los Apuntes del subsuelo, que: «Si Dostoievski no hubiese escrito nada más, se le habría recordado como uno de los maestros constructores del pensamiento moderno» (Steiner, 2002, 227). Predrag Cicovacki (cfr. 2014, 45) coincide con Steiner al mantener que, incluso si su autor hubiera abandonado la pluma finalizada esta obra, su fama como escritor habría quedado asegurada con ella. Recuerda, además, cómo para Konstantin Mochulsky este texto constituye el prólogo filosófico al ciclo de sus grandes novelas. Joseph Frank ( $c f r .1993,420)$ se suma al reconocimiento general del calado filosófico de esta obra cuando, en el capítulo que le dedica a los Apuntes del subsuelo dentro de su monumental biografía de Dostoievski en cinco tomos, destaca cómo el hombre del subterráneo se ha convertido en una figura arquetípica de la modernidad, capaz de poner al descubierto sus limitaciones y aporías.

No es difícil rastrear afirmaciones de parecida índole entre las monografías y los artículos de otros especialistas. El consenso en cuanto a la importancia, no sólo literaria, sino también filosófica, de este pequeño libro, parece unánime. Esto bastaría de por sí para justificar que este texto fuera objeto de atención en un congreso o publicación de filosofía, pero resulta además que los Apuntes del subsuelo es uno de los pocos grandes títulos de la historia de la literatura que fijan la atención en el cuerpo del protagonista ya desde la primera línea y eso lo convierte en un documento idóneo para ser abordado en el contexto del VII Congreso de la Sociedad Académica de Filosofía donde el cuerpo

1 También castellanizado como León Chestov. 
constituye el objeto central de reflexión. «Soy un ser humano enfermo...» («Я человек больной») es, efectivamente, el arranque de la obra. Y poco a poco vamos viendo cómo esa enfermedad que en principio parece física, pues el hombre del subsuelo se queja del hígado, tiene en verdad un arraigo moral. La segunda frase («Soy un ser humano malo», «Я злой человек») nos pone ya en la pista de esa conexión esencial. ${ }^{2}$

Los Apuntes del subsuelo han generado una bibliografía extensa y la crítica no siempre ha llegado a acuerdos en puntos esenciales del texto. Aun así, existe un amplio consenso en considerar que el libro fue concebido como un ataque contra el egoísmo racional y el determinismo materialista preconizados por Nikolái G. Chernyshevski y popularizados gracias a su novela ¿Qué hacer? (1863), convertida en el best seller del momento (cfr. Frank, 1993, 420-469; Llinares, 2011; y Scanlan, 2002). Hay pasajes de la creación de Dostoievski que remiten a episodios de ¿Qué hacer?, como el desafío a un funcionario en la avenida Nevski o el encuentro con la prostituta Liza. Asimismo, el primer sueño de Vera, protagonista de ¿Qué hacer?, es su liberación de un sótano, lugar simbólico en el que habitará el hombre del subsuelo y donde es probable que termine sus días Liza ( $c f r$. Černyševskij, 2004, 79-80).

Las ideas de Chernyshevski, autor también de El principio antropológico en la filosofía, fueron muy influyentes entre la llamada «generación joven», la de los años sesenta. Sin embargo, su visión de lo humano difícilmente podría ser más distante de la propugnada por Dostoievski. Influido por distintas tendencias europeas -el materialismo monista representado por P. H. T. d'Holbach y P. J. G. Cabanis, el cientificismo alemán (C. Vogt, J. Moleschott y L. Büchner) y el utilitarismo inglés de Jeremy Bentham y John Stuart Mill-, Chernyshevski propone un determinismo materialista ingenuo por el que el ser humano queda enteramente sometido a las leyes de la naturaleza, resultando la libertad, en último término, imposible. En cuanto a la dimensión moral, el autor de ¿Qué hacer? aboga por un utilitarismo en el que el bien y el mal se definen únicamente en términos de interés. Los hombres buscan aquello que les produce placer y satisface sus intereses egoístas. Así, una vez descubierto, mediante el conocimiento, en qué consiste el bien, es imposible obrar irracionalmente en contra de él, es decir, actuar en detrimento del propio interés. Este, además, termina por acomodarse racionalmente al interés de los demás, de modo que se logra una apacible armonía social, tal y como corresponde a la visión utópica de un socialista científico. Tanto Chernyshevski como Dmitri I. Písarev, otro influyente exponente del socialismo materialista ruso, estaban convencidos de que el racionalismo egoísta no provocaría la anarquía o el conflicto, sino la concordia y en último término la felicidad de todos.

2 A lo largo del presente artículo citaremos los Apuntes del subsuelo a partir de la traducción de Lidia Kúper de Velasco incluida en la edición de las Obras completas de Dostoievski (1969a) dirigida por Augusto Vidal para la editorial Vergara. Sin embargo, hemos consultado también el texto original ruso en la edición abreviada en quince tomos de las Obras completas publicada por la editorial Nauka en la soviética Leningrado (Достоевский, 1988-1996). Por ello hemos modificado ligeramente aquí la traducción de Lidia Kúper cuya solución es: «Soy un hombre enfermo... Un hombre malo» (Dostoievski, 1969a, 171). En efecto, «hombre» resulta más económico que «ser humano» desde el punto de vista lingüístico y, además, aligera el texto, mejorándolo incluso estéticamente. Sin embargo, hemos optado por traducir «человек/chelovék» como «ser humano» y no como «hombre» para dejar claro que se está empleando en ruso un término genéricamente no marcado a pesar de que quien toma la palabra es un varón. La diferencia no es banal, a nuestro entender, si lo que se pretende es hacer un análisis del texto desde un enfoque de antropología filosófica. 
Nada podía resultar más aberrante para Dostoievski que ver la libertad convertida en una quimera y el egoísmo erigido en modelo moral. Los Apuntes del subsuelo es, sobre todo en su primera parte, su respuesta al ideal defendido por Chernyshevski y sus correligionarios. El libro, que toma la forma literaria de la confesión, está dividido en dos secciones. El hombre del subterráneo tiene cuarenta años cuando escribe sus notas, en 1864, mientras que la acción de la segunda mitad ocurre en 1848, cuando es un joven de veinticuatro años. Esta cronología no es de ningún modo accesoria puesto que, además de convertir en perfecto coetáneo de Dostoievski al protagonista de los Apuntes del subsuelo, permite trazar el retrato de las dos generaciones que Turguénev había enfrentado ya de manera paradigmática en su novela Padres e hijos (1859). La generación de los padres se caracteriza por su humanitarismo y sus ideales romántico-sentimentales, en parte derivados de la lectura de las obras de los socialistas utópicos franceses y de los románticos sociales que habían encontrado eco entre la intelectualidad rusa. Recuerda Frank (cfr. 1993, 449-452) que la atmósfera cultural de los años cuarenta fomentaba entre los jóvenes ilustrados como el hombre del subsuelo una especie de egoísmo romántico artificial y un afán de superioridad sobre sus conciudadanos. Su vanidad es, precisamente, la que erige un muro entre él y quienes le rodean impidiendo que sus idílicas aspiraciones de amor romántico hacia la humanidad puedan concretarse en afecto hacia un ser humano concreto como Liza. El hombre del subsuelo es incapaz de un amor generoso y por eso, dieciséis años después de su encuentro con la joven, lo vemos retorcerse solo en su agujero, aquejado del hígado y víctima de una hiperconciencia que, aunque se debe a la asunción de las premisas de Chernyshevski, no le depara la existencia idílica que llevan los personajes de ¿Qué hacer?, sino que hace de él un ser escindido y profundamente desdichado.

En su novelística madura, Dostoievski no se enfrenta nunca a sus adversarios ideológicos rebatiéndolos con argumentos, sino que promueve que sus presuposiciones se desarrollen hasta sus últimas consecuencias, siempre destructivas, para dejar entrever, al borde del abismo, que otra salida es posible si el punto de partida es diferente. Esta técnica ya funciona en los Apuntes del subsuelo y por ello al hombre del subterráneo su intento por abrazar, como intelectual que es, las tesis por las que se decantan el utilitarismo y el determinismo racionalistas no le comporta la felicidad prometida, sino que lo convierte en un ser hiperconsciente siempre paralizado, al contrario que los hombres de acción retratados en ¿Qué hacer?. Según Chernyshevski, el libre albedrío ni existe ni puede hacerlo, pues todo aquello que los seres humanos creen realizar por propia voluntad responde en verdad a las leyes de la naturaleza. Este determinismo, en lugar de resultar tranquilizador, como pretendería Chernyshevski, genera una asfixia de las reacciones morales ordinarias y de la afectividad ligada a ellas, como puede ser el caso de la atribución de responsabilidad, el deseo de venganza o el sentimiento de vergüenza cuando nuestra conducta ha sido inapropiada. ¿A quién culpar si todo cuanto llevamos a cabo obedece a las leyes de la naturaleza? La razón le indica al hombre del subsuelo que la culpa o la indignación son completamente irracionales, pero aun así él experimenta estos sentimientos y ello es precisamente lo que lo convierte en humano. A causa de esto cobra sentido que no se ponga en tratamiento del hígado por despecho o que mantenga que se puede obtener placer de padecer un dolor de muelas ( $c f r$. Dostoievski, 1969a, 171-172, 181-182). En un universo en el que las leyes de la naturaleza han dejado reducido al ser humano a la total impotencia, protestar y quejarse 
es la única reacción digna posible, aunque resulte ridícula y autodestructiva. El hombre del subsuelo, aun sabiendo que no es libre, no puede dejar de comportarse como si lo fuera.

Afirma Predrag Cicovacki que le resulta imposible acercarse a los Apuntes del subsuelo sin que le venga a la mente la Lección de anatomía del Dr. Joan Deijman, que Rembrandt pintó en 1656. De hecho, propone leer la novela breve de Dostoievski no tanto como si se tratara de una confesión, que es siempre la revelación voluntaria de los errores cometidos, sino como si estuviéramos ante una disección anatómica de la naturaleza humana, hábilmente acometida por el bisturí del escritor ruso. Si en la primera parte de los Apuntes del subsuelo la operación se focaliza en la razón, en la segunda son las pasiones las que quedan sometidas a escrutinio. De hecho, Cicovacki (cfr. 2014, 45-72) titula los epígrafes dedicados a examinar cada una de las dos secciones, respectivamente, «Una anatomía de la razón» y «Una anatomía de la pasión». Nosotros no vamos a seguir su análisis, pero sí recogeremos algunas de sus intuiciones para analizar la significación del cuerpo en esta obra de Dostoievski.

La Lección de anatomía del Dr. Joan Deijman (1656) fue en origen un cuadro inmenso del que sólo nos ha llegado la parte central, pues el resto quedó destruido en un incendio fatal que tuvo lugar en 1731. Encargado para la Sala de Anatomía de Ámsterdam, el lienzo representa al Dr. Joan Deijman en el momento de realizar la disección del cerebro del condenado Joris Fonteijn. La ciudad holandesa vivía por aquel entonces un boom económico que implicó un gran auge del conocimiento. Los avances en anatomía, además de interesar a médicos y estudiantes, dieron lugar a la celebración de espectáculos públicos de disección a los que se podía acceder previo pago. Este es el contexto que reproduce la obra de Rembrandt. A diferencia de lo que sucedía en la magistral Lección de anatomía del Dr. Nicolaes Tulp (1632), pintada veinticuatro años antes, no es ya en los músculos del cadáver donde se concentra la atención de los asistentes a la intervención, sino en la sede del pensamiento ya extinto. Del cuerpo se han extirpado los intestinos y el estómago, por lo que en el lugar del vientre sólo contemplamos una oscura caverna vacía. Ni rastro queda en ese agujero de las funciones vitales que alguna vez hallaron allí su espacio. El rostro del reo, sin embargo, conserva toda su humanidad. Rembrandt parece haberse esmerado para que las facciones del cadáver no sean menos reconocibles y expresivas que las del profesor que está observando en primer plano la operación y, suponemos, que las del propio Dr. Deijman si su figura no hubiera quedado consumida en el incendio que sufrió la tela. Así, en el mismo cuadro donde se ensalzan los progresos de la ciencia, se descubre un reconocimiento implícito de que perdura algo que se resiste a quedar reducido a la carne que desgaja sin esfuerzo el bisturí. Ese algo se concentra en la expresión de un rostro humano que sorprendemos en alguien o algo (aquí el lenguaje nos juega malas pasadas) que ya sólo debería ser cadáver.

Señala Cicovacki $(c f r .2014,65)$ que en los Apuntes del subsuelo se da un agudo contraste entre la forma de presentación del hombre del subsuelo, tan impersonal que ni siquiera se nos revela su nombre, y la de Liza, que ocupa varias líneas y se recrea en particular en el análisis de su rostro. Es precisamente el protagonista y autor de los apuntes quien examina con detenimiento las facciones de la joven justo antes de que, por casualidad, se vea a sí mismo reflejado en un espejo. Su rostro agitado, pálido, vicioso, ruin, con el pelo enmarañado, le parece entonces extremadamente repulsivo y se alegra de que así sea pues ello implica una mayor tortura para la mujer a la que va a poseer a continuación ( $c f r$. 
Dostoievski, 1969a, 247). Resentido por la humillación que ha supuesto su reencuentro con antiguos compañeros del colegio, el hombre del subsuelo se desquita con una criatura más débil que él mismo. No conforme con someterla físicamente, al percatarse de que la muchacha se avergüenza de la vida que ha empezado a llevar y del acto al que acaba de prestarse, comienza un discurso con el que consigue torpedear la débil defensa tras la cual ella se parapeta. Su fingida indiferencia termina por resquebrajarse cuando el hombre del subsuelo traza el retrato descarnado del destino probable que le aguarda. Con crueldad indisimulada le cuenta que esa misma mañana gélida ha visto cómo sacaban el féretro de una prostituta de un sótano en la plaza Sennáia. Añade que seguramente sus enterradores, sin cesar de echar maldiciones por las dificultades de su tarea en lo más crudo del invierno, habrán terminado por dejar su ataúd en una fosa encharcada. Con toda probabilidad en unos años, la joven todavía orgullosa que ahora tiene ante sí, recién aterrizada en el prostíbulo, ocupará el lugar de esa mujer caída. Sus sepultureros, desconsiderados por su condición, no tendrán entonces reparo en bajar su ataúd de lado o inclinado con los pies hacia delante, apresurándose por acabar e ir a calentarse lo antes posible a la taberna.

Temblorosa y muy afectada por sus palabras, Liza, haciendo acopio del poco amor propio que le queda, le muestra a su interlocutor la carta que un estudiante, probablemente de medicina, le ha escrito como una grandilocuente declaración de amor. La referencia al estudiante de medicina no es gratuita, puesto que esta era la ciencia con mayúsculas cuando el hombre del subsuelo redacta sus anotaciones, en los años sesenta. El nihilista Bazárov, protagonista de la célebre Padres e hijos de Turguénev, es precisamente un estudiante de medicina recién licenciado. Además, la insistencia del hombre del subterráneo en padecer la afección del hígado o el dolor de muelas es una forma de rebelión contra una ciencia que representaba de forma paradigmática los ideales de racionalidad y progreso.

Antes de que Liza se marche, embriagado por su propia elocuencia, el hombre del subsuelo le da su dirección invitándola a que lo visite para que pueda ayudarla a enderezar el rumbo de su vida. Sin embargo, tan pronto como se desvanece el efecto narcótico de su retórica libresca, nuestro protagonista queda aterrado por la idea de que la joven le haga caso y se vea obligado a recibirla en su casa, poniendo ante sus ojos la vergonzosa realidad de su existencia miserable. Recobra la calma cuando, transcurridos unos días, Liza no aparece. Sin embargo, al final ella hace acto de presencia y descubre cómo su héroe salvador vive en un agujero hediondo y está constantemente atemorizado por el fuerte carácter y las firmes exigencias de su propio criado. El hombre del subsuelo se siente humillado ante su visitante y su mezquina reacción consiste en revelarle que cuando la conoció en el prostíbulo la utilizó para vengar en ella la ofensa que le habían causado sus antiguos compañeros de escuela sin permitirle el desagravio. La respuesta natural que él aguarda de Liza tras esta vil confesión es la rabia y el desprecio, pero la conducta de ella lo descoloca, pues, en lugar de atacarlo, se arroja a sus brazos para darle consuelo y los dos terminan llorando juntos. Incapaz de concebir el amor más que en términos de sumisión y dominio, el hombre del subsuelo responde colocándole a Liza un billete de cinco rublos en la mano. La joven se marcha sin llevarse el dinero y, aunque un inesperado remordimiento le hace correr en su búsqueda, el hombre del subsuelo no da con ella. Ya de regreso a casa se consuela con una retorcida racionalización que consiste en pensar que el recuerdo amargo de su ofensa acabará por provocar en la muchacha una purificación 
a través del sufrimiento. Cuando se pregunta «iqué es preferible, una felicidad barata, o unos sufrimientos elevados?» (Dostoievski, 1969a, 284), plantea una disyuntiva perversa.

En la primera parte de los Apuntes del subsuelo su protagonista reivindicaba el sufrimiento que implicaba no querer sanar del hígado o mitigar un dolor de muelas como expresión de la libertad frente a la tiranía impuesta por el determinismo y, por tanto, como último reducto de una conciencia moral. Sin embargo, su comportamiento con Liza muestra de qué manera el masoquismo, que podía encontrar su razón de ser como forma de rebelión contra las leyes de la naturaleza, pierde toda legitimidad cuando se invierte en sadismo, de modo que el sufrimiento infligido a los demás pretende justificarse como un medio para purificarlos. Esta inversión es el peligro inherente al egoísmo. Por ello, una vez que se ha puesto de manifiesto el absurdo de las tesis del determinismo y el utilitarismo racionalistas, no basta con llegar a la conclusión de que el mayor interés del hombre ha de radicar, contrariamente a lo propugnado por Chernyshevski, en su libertad. El libre albedrío es lo que nos convierte en seres humanos, pero la obra futura de Dostoievski mostrará cómo quien escoge rechazar repetidamente el mensaje de amor de Cristo termina por aniquilarse. El hombre del subsuelo no queda condenado a su agujero porque las tesis del egoísmo racional defendido por Chernyshevski sean certeras y no haya otra salida para él, sino porque fue incapaz de responder al amor que le ofreció Liza, un ser humano más doliente que él mismo.

La primera parte de la novela breve de Dostoievski contiene un capítulo, el décimo, que fue gravemente mutilado por la censura. En él, según refiere Frank, Dostoievski manifestó haber expresado la idea fundamental de su obra, que definió como la necesidad de la fe y de Cristo. Sin embargo, los pasajes en los que lo hizo fueron suprimidos y jamás se restauraron (cfr. Frank, 1993, 445-449). La crítica ha discutido mucho sobre las posibles razones por las que el escritor optó por no devolverle al libro la forma original que había concebido para él en posteriores reediciones del texto que se hicieron cuando él aún vivía. No obstante, esta polémica entre especialistas no nos interesa aquí. Lo que sí quisiéramos, en cambio, es proponer la tesis de que la lectura en contrapunto de la Lección de anatomía del Dr. Deijman y los Apuntes del subsuelo puede ayudarnos a dilucidar cuál era ese pensamiento esencial de su novela breve que Dostoievski no llegó a plasmar.

Como se ha señalado anteriormente, su hiperconciencia mantiene al hombre del subsuelo alejado de los hombres de acción, es decir, de los personajes dichosos de la novela de Chernyshevski. Si él habita en un rincón oscuro, Vera sueña con un futuro en el que la humanidad vivirá en un palacio de acero y cristal, un edificio funcional y luminoso, de amplios ventanales y repleto de espejos, rodeado de refrescantes jardines y huertos fértiles. Se tratará de un paraíso en la Tierra en el que los trabajos pesados estarán tecnificados y la comida, que nunca faltará, será gratis. Este espacio con el que fantasea la protagonista de ¿Qué hacer? está inspirado en el Palacio de Cristal erigido en el Hyde Park londinense con motivo de la Exposición Universal de 1851. Esta construcción, que acabaría destruida en un incendio en 1936, asombró al mundo occidental y se convirtió en un símbolo de modernidad y progreso. El propio Dostoievski visitó este hito arquitectónico en 1862, cuando ya había sido trasladado a Sydenham Hill y albergaba, de nuevo, la Exposición Universal de aquel año. En el capítulo titulado «Baal» dentro de sus Notas de invierno sobre impresiones de verano, el escritor ruso se refiere a su viaje a Londres y, aparte de quejarse de las multitudes que pueblan la ciudad, arremete contra la fe en la civilización y la técnica que tiene su 
símbolo en esa inmensa mole de acero y cristal ( $c f r$. Dostoevskij, 2008, 49-69). El hombre del subsuelo hereda de su creador esta aversión por el emblema de un nuevo ideal utópico y protesta no tanto contra la utilidad del edificio de cristal, sino contra el empeño por hacer de él la meta hacia la que debe dirigirse la humanidad. Quizá se trate de un edificio bien diseñado y de provecho, pero tomarlo por el fin hacia el que tender equivale a tomar por palacio lo que no es más que un gallinero (cfr. Dostoievski, 1969a, 200).

Dostoievski identifica el verdadero Palacio de Cristal con la necesidad de la fe y de Cristo y, aunque en los Apuntes del subsuelo este punto esencial no quede más desarrollado, sí resulta claro, en primer lugar, que el auténtico palacio presupone la existencia de la libertad como condición humana inalienable. Sabemos, además, que el hombre del subsuelo busca con anhelo ese ideal, pero que no lo puede hallar ${ }^{3}$. El motivo de ello se nos revela en la segunda parte de la novela breve, pues su incapacidad para amar a Liza y su intento de justificar el sufrimiento que le ha causado escudándose en que ese dolor la purificará son los que alejan al hombre del subsuelo del verdadero palacio. Después de que ella lo abrace para consolarlo, él queda yaciendo boca abajo en el sofá y teme el momento en que, al darse la vuelta, tendrá que afrontar el rostro y la mirada de la joven ( $c f r$. Dostoievski, 1969a, 280). Al darle el billete de cinco rublos, el hombre del subsuelo olvida que Liza, como el difunto Joris Fonteijn del cuadro de Rembrandt, tiene un rostro e ignorarlo equivale a una deshumanización que es la auténtica derrota frente a las leyes de la naturaleza. No en vano, el hombre del subsuelo ha de recurrir a una racionalización -la idea de que el tormento que le ha provocado a Liza es ventajoso para ella- a fin de acallar su conciencia moral.

El cadáver del condenado en la Lección de anatomía del Dr. Joan Deijman guarda similitud, tanto por la posición como por el detalle en el dibujo de las facciones, con el cuerpo de Jesús tal como aparece representado en la Lamentación sobre Cristo muerto (ca. 1475-1490, datación incierta) de Andrea Mantegna. El artista italiano pinta la figura de Cristo en un potente escorzo por el que la atención del espectador se concentra en el rostro. Además, se exhiben sin tapujos los signos del dolor tras el tormento. Tres figuras acompañan al difunto y lloran su muerte. Se trata de la Virgen María, San Juan Evangelista y una mujer doliente, apenas visible, que podría ser María Magdalena. En cualquier caso, entre los estudiosos ha cobrado cierta fuerza la hipótesis de que estos tres personajes sean un añadido posterior realizado por otro autor menos dotado. Esto significaría que Mantegna optó por retratar a Cristo solo. Esto mismo fue lo que hizo Hans Holbein el Joven en su Cristo muerto (1521), pero acentuando muchísimo las marcas del martirio. Dostoievski quedó fuertemente impresionado cuando vio el cuadro en Basilea en 1867 y así lo recogió en su diario su segunda esposa, Anna Grigorievna ( $c f r$. Frank, 1997, 290-292). Fue tan potente el impacto que esta tela tuvo en el escritor que la hizo aparecer en El idiota (1868-1869), la más personal de todas sus novelas de madurez. Frente a una copia del lienzo, el príncipe Myshkin exclama

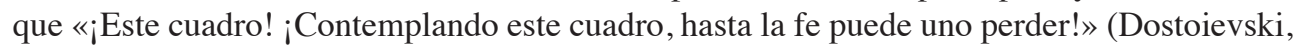
1969b, 220). Cuando las leyes de la naturaleza hacen gala de todo su poderío, reduciendo a sangre seca, moratones y hematomas el cuerpo mismo de Jesús, es cuando la libertad

3 Cfr. Dostoievski, 1969a, 202: «[...] sé muy bien, lo mismo que dos por dos son cuatro, que lo mejor no es el subsuelo, sino algo distinto, completamente distinto que yo anhelo, pero que no acabo de encontrar. ¡ $\mathrm{Al}$ diablo el subsuelo!» 
esencial del ser humano se pone en juego y el auténtico Palacio de Cristal está a su alcance. Ante el lienzo de Holbein, sólo la fe puede conducir a la elección libre de aceptar el mensaje de Cristo, precisamente porque el sentido del sufrimiento del Dios hecho hombre no es pensable mediante argumentos racionales y por tanto no se deja comprender. El ser humano, que nunca podrá ser asimilable a la tecla de un piano o al tornillito de un órgano ( $c f r$. Dostoievski, 1969a, 196), es libre para creer y también para amar, pero siempre estará tentado de no hacerlo y, por eso, es la suya una condición trágica.

\section{Bibliografía}

Berdiaev, Nikolay (2008): El espíritu de Dostoyevski, trad. cast. de Olga Trankova Tabatadze con la colaboración de Sebastián Montiel y Artur Mrowczynski-Van Allen, Editorial Nuevo Inicio, Granada.

Černyševskij, Nikolaj Gavrilovič (2004): Che fare?, trad. it. de Federico Verdinois, Garzanti, Milano.

Chestov, León (1949): La filosofía de la tragedia: Dostoievski y Nietzsche, Emecé, Buenos Aires.

Cicovacki, Predrag (2014): Dostoevsky and the Affirmation of Life, Transaction Publishers, New Jersey.

Dostoievski, F. M. (1969a): Apuntes del subsuelo, en: Id., Obras completas, vol. III, ed. cast. dirigida y prologada por Augusto Vidal, con un estudio preliminar de José L. Aranguren, Vergara, Barcelona, pp. 169-286.

Dostoievski, F. M. (1969b): El idiota, trad. cast. de Augusto Vidal, en: Id., Obras completas, vol. IV, Vergara, Barcelona.

Dostoevskij, Fëdor (2008): Note invernali su impressioni estive, trad. it. de Serena Prina, Feltrinelli, Milano.

Достоевский, Ф. М. (1988-1996): Записки из подполья. В: Собрание сочинений в 15 томах, том 4, Наука, Ленинград.

Frank, Joseph (1993): Dostoievski: La secuela de la liberación, 1860-1865, trad. cast. de Juan José Utrilla, F.C.E., México.

Frank, Joseph (1997): Dostoievski: Los años milagrosos 1865-1871, trad. cast. de Mónica Utrilla, F.C.E., México.

Llinares Chover, Joan B. (2011): «La crítica de F. Dostoievski a la antropología de N. Chernyshevski. Memorias del subsuelo como réplica a ¿Qué hacer?», en: J. San Martín y T. Domingo Moratalla (eds.), La imagen del ser humano. Historia, literatura y hermenéutica, Biblioteca Nueva, Madrid, pp. 131-141.

Nietzsche, Friedrich (1998): Crepúsculo de los ídolos, trad. cast. de Andrés Sánchez Pascual, Alianza, Madrid.

Rivera León, Lorena (2015): El amor en Dostoievski: un estudio desde la antropología filosófica, tesis doctoral, Universitat de València, Valencia.

Scanlan, James P. (2002): Dostoevsky the Thinker, Cornell University Press, Ithaca (New York).

Steiner, George (2002): Tolstói o Dostoievski, trad. cast. de Agustí Bartra, Siruela, Madrid. 
